\title{
Delphinid echolocation click detection probability on near-seafloor sensors
}

\author{
Kaitlin E. Frasier ${ }^{\mathrm{a})}$ and Sean M. Wiggins \\ Scripps Institution of Oceanography, 9500 Gilman Drive, La Jolla, California 92093-0205, USA \\ Danielle Harris, Tiago A. Marques, ${ }^{\text {b) }}$ and Len Thomas \\ Centre for Research into Ecological and Environmental Modelling, University of St Andrews, \\ The Observatory, Buchanan Gardens, Fife KY16 9LZ, United Kingdom \\ John A. Hildebrand \\ Scripps Institution of Oceanography, 9500 Gilman Drive, La Jolla, California 92093-0205, USA
}

(Received 9 February 2016; revised 11 July 2016; accepted 8 August 2016; published online 22 September 2016)

The probability of detecting echolocating delphinids on a near-seafloor sensor was estimated using two Monte Carlo simulation methods. One method estimated the probability of detecting a single click (cue counting); the other estimated the probability of detecting a group of delphinids (group counting). Echolocation click beam pattern and source level assumptions strongly influenced detectability predictions by the cue counting model. Group detectability was also influenced by assumptions about group behaviors. Model results were compared to in situ recordings of encounters with Risso's dolphin (Grampus griseus) and presumed pantropical spotted dolphin (Stenella attenuata) from a near-seafloor four-channel tracking sensor deployed in the Gulf of Mexico $\left(25.537^{\circ} \mathrm{N} 84.632^{\circ} \mathrm{W}\right.$, depth $\left.1220 \mathrm{~m}\right)$. Horizontal detection range, received level and estimated source level distributions from localized encounters were compared with the model predictions. Agreement between in situ results and model predictions suggests that simulations can be used to estimate detection probabilities when direct distance estimation is not available.

(C) 2016 Acoustical Society of America. [http://dx.doi.org/10.1121/1.4962279]

[WWA]

Pages: $1918-1930$

\section{INTRODUCTION}

One common goal of marine mammal studies is to estimate population densities to aid stock assessments and management. An increasingly common approach to density estimation is to employ passive acoustic monitoring (PAM) to provide long-term recordings of marine mammal sounds. The most broadly used density estimation method, distance sampling, requires the distance between detections (source, a vocalizing animal) and a hydrophone sensor (receiver) to be reliably estimated (Marques et al., 2009; Thomas et al., 2010; Marques et al., 2013). In these cases, the probability of detecting an acoustic signal (cue) can be estimated using distance sampling methods (Buckland et al., 2001), and density estimates are derived from knowledge of cue production rates and cue counts (Buckland et al., 2006). However, it is difficult to estimate source-receiver distances to echolocating delphinids because of click characteristics such as signal directionality, high-frequency composition which is easily attenuated with distance, and short duration. Also, their clicking behavior often results in interference between simultaneously vocalizing animals, especially since delphinids tend to travel and forage in large groups, producing large numbers of high-frequency, directional echolocation

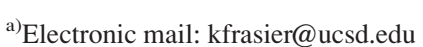

b) Also at: Centro de Estatística e Aplicações da Universidade de Lisboa, Bloco C6, Piso 4, 1749-016, Lisboa, Portugal
}

clicks with variable frequency content and source levels. Because of these confounding factors, the range of a vocalizing dolphin to a sensor cannot be estimated solely from received click characteristics.

Estimating the detection probability via the simulation of the detection process itself, provides an alternative to distance sampling, in cases where distances cannot be reliably estimated. Monte Carlo simulation methods (Metropolis and Ulam, 1949) have been used to estimate detection probabilities for beaked, blue, and humpback whale cues (Küsel et al., 2011; Harris, 2012; Helble et al., 2013b; Hildebrand et al., 2015). Using this approach, sources are placed at randomly selected locations around a receiver. The decision whether or not a cue would be detected is based on signal characteristics, acoustic propagation models, receiver characteristics and detector performance. The simulation is repeated over many iterations to generate a range-dependent map of detection probabilities in the vicinity of the sensor. By iterating the model in this way, model parameter estimates can be repeatedly drawn from parameter ranges reported in the literature, to incorporate variability and uncertainty into detection probability estimates.

Knowledge of a signal detector's ability to identify the animals' sound is needed. Previous studies have embedded simulated calls in noise (Helble et al., 2013a), used signals with known source levels recorded at known distances (Ward et al., 2011) or used logistic regression to model probability of detection as a function of signal to noise ratio 
(SNR) (Küsel et al., 2011) to empirically determine a detector's performance. An alternate approach for echolocating animals is to implement a simplified click detector, which functions predictably based on a constant amplitude threshold. If this threshold is an absolute measure of sound pressure amplitude (peak-to-peak $\mathrm{dB}$ re $1 \mu \mathrm{Pa}$ ) from calibrated hydrophones, the performance of the detector can be estimated within a simulation framework. False positive rates can be computed by systematically reviewing a subset of detections (e.g., every $N$ th detection).

Click characteristics, including frequency content, beam-width, and source level vary between delphinid species (e.g., Fish and Turl, 1976; Au et al., 1986; Au et al., 1995; Au and Herzing, 2003; Madsen et al., 2004), and the distributions of these parameters influence detection probabilities (Hildebrand et al., 2015). Species-dependent behaviors including depth distributions, group size, and dive synchrony (e.g., Baird et al., 2001; Heide-Jørgensen et al., 2002; Scott and Chivers, 2009; Wells et al., 2009) are also expected to affect detectability. Another challenge is that delphinid echolocation click models are not yet able to predict signal characteristics, such as energy output, duration and frequency content, as a function of animal orientation. Likewise, animal-attached acoustic tag recordings from delphinids are sparse, and are of limited utility because they typically lack coverage for a range of orientations of the tagged animal and the recordings may not be representative of the far-field signal because of tag placement on the animal.

Two primary density estimation strategies exist for marine mammals using stationary passive acoustic sensors: cue counting and group counting (Buckland et al., 2001; Buckland et al., 2006). Cue counting methods use individual cues as the basic unit for density estimation. The number of cues detected over a period of time is converted into an estimate of animal density. Group counting methods for fixed instruments use a small window of time, or snapshot, as the basic unit for density estimation (e.g., Hildebrand et al., 2015). A window is considered positive if animals are detected during that time period and negative otherwise. The number of positive windows is converted into an estimate of animal density, by assuming that a positive window equates to presence of an animal group. Mean group sizes can be used to convert group-counts into estimated numbers of individual animals.

Both cue and group counting simulation methods require knowledge of cue properties, animal distributions in space, and local oceanographic conditions. Cue counting has the advantage of relying on only two behavioral parameters that affect the probability of detecting a click: animal depth and vertical orientation (pitch) in the water column (assuming that animal azimuthal orientation, or yaw, is random relative to the sensor). Disadvantages of cue counting appear in later steps of the density estimation. These include sensitivity to concentrated bouts of false positives, risk of detector saturation, and that cue production rates may vary with animal density (e.g., Götz et al., 2006). In contrast, group counting methods are relatively insensitive to detector saturation, cue rate variation and occasional bouts of false positives.
However, simulation of group detectability requires a group behavior model to incorporate vocalization probability (e.g., Marques et al., 2013) and group orientation.

Beginning in 2010, single-sensor PAM devices, Highfrequency Acoustic Recording Packages (HARPS), have been deployed in the Gulf of Mexico (GOM), to monitor effects of the Deepwater Horizon oil spill on marine mammal populations. In this paper, a framework is developed for estimating delphinid echolocation click detection probabilities, as a preliminary step toward delphinid density estimation using single-sensor recordings.

Two simulations, one estimating cue detection probabilities, and the other estimating group detection probabilities, are developed and discussed. Both models are designed to simulate the performance of a simple echolocation click detector governed by a waveform peak-to-peak amplitude threshold. Detection probabilities are compared for two general categories of pelagic delphinids: deep and shallow divers.

Model results were compared with in situ data collected at a site off of the southwestern coast of Florida. In situ detection ranges and click parameters were obtained from a short-term deployment of a multi-sensor PAM device with localization capabilities. Model distributions of received levels (RL), detection ranges, and source levels (SL) are compared with in situ data from Risso's dolphin (Grampus griseus) and presumed pantropical spotted dolphin (Stenella attenuata).

\section{METHODS}

The detectability simulation algorithm consisted of two nested loops (hereafter termed outer and inner) in a Monte Carlo framework designed after Küsel et al. (2011). A bootstrapping procedure was used to vary parameters across model iterations: Within each iteration, $N$, of the outer loop, each input parameter $(P)$ was defined by a mean $\left(\mu_{P N}\right)$ and standard deviation $\left(\sigma_{P N}\right)$ drawn from uniform distributions, where the limits were obtained from the literature (Table I). Input parameters were related to acoustic characteristics of the signal and to animal behavior. In the inner loop, each source was assigned parameter values drawn from probability distributions (normal, log-normal, or uniform) defined by $\mu_{P N}$ and $\sigma_{P N}$ (Table I). Five hundred iterations of the outer loop, each initiating $10^{4}$ iterations $(n)$ of the inner loop, were run for each detection probability scenario. Each iteration $N$ of the outer loop was considered a single simulation. To illustrate this procedure, consider a hypothetical parameter $X$ which is expected to be normally distributed, with a mean $\left(\mu_{X}\right)$ between 3 and 5 with a standard deviation $\left(\sigma_{X}\right)$ between 0.5 and 1 , based on a literature review. For the $N$ th iteration of the outer loop, $\mu_{N X}=$ unifrand([3,5]) and $\sigma_{N X}=\operatorname{unifrand}([0.5,1])$, where unifrand() is a uniform random number generator which accepts minimum and maximum values as inputs. Within the $N$ th simulation, $10^{4}$ values for $X$ are sampled from a normal distribution as $X_{n}=\operatorname{normrand}\left(\mu_{N X}, \sigma_{N X}\right)$, where normrand() generates normally distributed random numbers given a mean and standard deviation. This approach allows 
TABLE I. Literature-based acoustic and behavior parameters used in Monte Carlo simulations of $\mathrm{D}^{\mathrm{a}}$ and $\mathrm{S}^{\mathrm{b}}$ diving delphinid detectability. Parameters unique to the click and group-based methods are listed separately, while some parameters are common to both methods. For each outer loop of the simulation, a mean and standard deviation for each parameter were drawn from a random uniform distribution between the listed ranges associated with that parameter. A second random distribution of the type listed under "Distribution" was then generated for each parameter for each inner loop iteration using the selected mean and standard deviation. For log-normal variables (depth), mean and standard deviation are of the variable's natural logarithm.

\begin{tabular}{|c|c|c|c|c|c|c|}
\hline & Parameter & Dive Category & Mean $(\mu)$ & Standard Deviation $(\sigma)$ & Distribution & References \\
\hline \multirow[t]{8}{*}{ Click Model } & \multirow[t]{2}{*}{ Dive depth (m) } & $\mathrm{D}$ & $2-3.5$ & $1-1.5$ & $\begin{array}{l}\text { Log-normal, right } \\
\text { truncated at } 500 \mathrm{~m}\end{array}$ & \multirow[t]{2}{*}{$1^{\mathrm{c}}$} \\
\hline & & S & $1.5-3$ & $0.5-1$ & $\begin{array}{l}\text { Log-normal, right } \\
\text { truncated at } 250 \mathrm{~m}\end{array}$ & \\
\hline & Orientation: Elevation & $\mathrm{D}, \mathrm{S}$ & $\pm 0^{\circ}$ & $2-20^{\circ}$ & $\begin{array}{l}\text { Normal, Left } \\
\text { truncated at } 0^{\circ}\end{array}$ & $\begin{array}{l}\text { Parameter currently } \\
\text { undocumented in the } \\
\text { literature }\end{array}$ \\
\hline & Orientation: Azimuth & $\mathrm{D}, \mathrm{S}$ & $\pm 0^{\circ}-359^{\circ}$ & $\mathrm{n} / \mathrm{a}$ & Uniform & Simulation assumption \\
\hline & $90^{\circ}$ off-axis TL $(\mathrm{dB})^{\mathrm{d}}$ & $\mathrm{D}, \mathrm{S}$ & $28-30$ & $\mathrm{n} / \mathrm{a}$ & Uniform & $2^{\mathrm{e}}$ \\
\hline & $180^{\circ}$ off-axis TL (dB) & $\mathrm{D}, \mathrm{S}$ & $30-32$ & $\mathrm{n} / \mathrm{a}$ & Uniform & 2 \\
\hline & \multirow[t]{2}{*}{ Directivity (dB) } & $\mathrm{D}$ & $25-29$ & \multirow[t]{2}{*}{$\mathrm{n} / \mathrm{a}$} & Uniform & \multirow[t]{2}{*}{2} \\
\hline & & S & $20-22$ & & & \\
\hline \multirow[t]{5}{*}{ Group Model } & \multirow[t]{2}{*}{ Max dive depth (m) } & $\mathrm{D}$ & $2.5-3.5$ & $1-1.5$ & $\begin{array}{l}\text { Log-normal, Right } \\
\text { truncated at } 500 \mathrm{~m}\end{array}$ & \multirow[t]{2}{*}{1} \\
\hline & & $\mathrm{S}$ & $2-3$ & $0.5-1$ & $\begin{array}{l}\text { Log-normal, Right } \\
\text { truncated at } 250 \mathrm{~m}\end{array}$ & \\
\hline & Min off-axis TL (dB) & $\mathrm{D}, \mathrm{S}$ & $23-27$ & $2-5$ & Normal & 2 \\
\hline & Rotation in Elevation & $\mathrm{D}, \mathrm{S}$ & $\pm 10^{\circ}-30^{\circ}$ & $5^{\circ}-15^{\circ}$ & Normal & $\begin{array}{c}\text { Parameter currently } \\
\text { undocumented in the literature }\end{array}$ \\
\hline & Rotation in Azimuth & $\mathrm{D}, \mathrm{S}$ & $\pm 90^{\circ}-135^{\circ}$ & $10^{\circ}-20^{\circ}$ & Normal & $\begin{array}{c}\text { Parameter currently } \\
\text { undocumented in the literature }\end{array}$ \\
\hline \multirow[t]{4}{*}{ Both Models } & \multirow[t]{2}{*}{ Peak Frequency (kHz) } & $\mathrm{D}$ & 32 & \multirow[t]{2}{*}{$\mathrm{n} / \mathrm{a}$} & \multirow[t]{2}{*}{ none } & \multirow[t]{2}{*}{ This dataset } \\
\hline & & $\mathrm{S}$ & 36 & & & \\
\hline & \multirow[t]{2}{*}{ Source level $\left(\mathrm{dB}_{\mathrm{pp}}\right)$} & $\mathrm{D}$ & $220-230$ & \multirow[t]{2}{*}{$3-5$} & \multirow[t]{2}{*}{ Normal } & \multirow[t]{2}{*}{2} \\
\hline & & $\mathrm{S}$ & $210-220$ & & & \\
\hline
\end{tabular}

${ }^{\mathrm{a}} \operatorname{Deep}(\mathrm{D})$.

${ }^{\mathrm{b}}$ Shallow (S).

${ }^{\mathrm{c}}$ Scott and Chivers, 2009; Wells et al., 2009.

${ }^{\mathrm{d}}$ Transmission loss (TL).

${ }^{\mathrm{e}}$ Fish and Turl, 1976; Rasmussen et al., 2002; Au and Herzing, 2003; Rasmussen et al., 2004; Au et al., $2012 \mathrm{a}$.

uncertainty in the true value of the parameters to propagate into model predictions.

\section{A. Cue counting method}

The cue-based detection probability simulation was designed to estimate the probability of the sensor detecting individual clicks. The simulated sensor was assumed to be located at the same location and depth as the sensor deployed for the in situ experiment $\left(25.537^{\circ} \mathrm{N}, 84.632^{\circ} \mathrm{W}\right.$, depth $1220 \mathrm{~m}$ ). Within a single iteration of the model, $10^{4}$ source positions in the horizontal plane were randomly selected around the sensor in a circular area with a $5 \mathrm{~km}$ radius. Transmission loss calculations (see Sec. II E, below) indicated that echolocation clicks would not be detectable outside of this area.

Each source was assigned a depth, drawn from a lognormal probability distribution with parameters generated from the outer loop bootstrapping procedure, values for which were based on species-specific dive behavior found in the literature (Table I; Scott and Chivers, 2009; Wells et al., 2009). Sources were then assigned a body angle in the vertical plane (pitch), and an orientation in the horizontal plane (yaw). Yaw was chosen from a uniform distribution in which all orientations relative to the sensor were equally likely $\left(0^{\circ}\right.$ to $\left.359^{\circ}\right)$. Pitch angle was drawn from a lefttruncated normal distribution with a mean of $0^{\circ}$ (body parallel to the seafloor) and a standard deviation selected from a uniform distribution between $2^{\circ}$ and $20^{\circ}$ upon each iteration of the model. If available in the future for delphinids, pitch angle distributions could be derived from tags. Because pitch was undocumented in the literature, these standard deviation limits were chosen to cover a broad range of possible orientation behaviors.

Sources were assigned on-axis source levels and beam directivities drawn from distributions defined by values reported in the literature (Fish and Turl, 1976; Rasmussen et al., 2002; Au and Herzing, 2003; Rasmussen et al., 2004; Au et al., 2012a; Smith et al., 2016). Beam directivity was drawn from a uniform distribution and held constant in each simulation, but varied between simulations. Directivities were used to calculate three-dimensional beam patterns based on a piston model (Au, 1993; Zimmer et al., 2005) in terms of transmission loss. The pitch and yaw of each 
source's beam axis relative to the receiver were used to identify the amount of orientation-dependent transmission loss, and this was subtracted from the on-axis source level. The piston model is an approximation, and does not realistically predict amplitudes at large off-axis angles. To compensate for this, mean values for beam amplitudes at $90^{\circ}$ and $180^{\circ}$ off-axis angles were drawn from a uniform distribution based on beam patterns in the literature ( $\mathrm{Au}$ and Moore, 1986; Au et al., 2012b). The off-axis beam shape was completed by interpolating between the $90^{\circ}$ and $180^{\circ}$ amplitude values. Predicted received levels at the sensor were computed for a click produced at each modeled source position, using the parameters assigned to each source, and modelbased transmission loss estimates at the click peak frequency (see Sec. II E, below). Clicks with RLs greater than $115 \mathrm{~dB}_{\mathrm{pp}}$ re: $1 \mu \mathrm{Pa}$ were considered detectable, mimicking the behavior of an amplitude-based click detector. This threshold choice was based on a manual review of the detection data to determine an RL level at which the detector's false negative rate was negligible false negatives occur when clicks which exceed the minimum RL threshold are missed. The detection probability $\left(P_{d e t}\right)$ associated with each simulation was computed as the ratio of clicks detected to the total number of simulated clicks.

\section{B. Group counting method}

The group-based detection probability model estimated the probability of detecting a group of echolocating clicking animals during a $5 \mathrm{~min}$ window. This approach, sometimes referred to as a snapshot method (Kyhn et al., 2012), requires the assumption that animals do not move in-to or out-of the detection area during a short time window, and therefore source locations were held stationary in the simulation (Buckland et al., 2006). The 5 min window was chosen as an interval over which animals could be assumed to be stationary given average delphinid swim speeds between 4 and $10 \mathrm{~km} / \mathrm{h}$ (e.g., Scott and Chivers, 2009; Kruse et al., 1999; see Sec. IV for implications of the stationarity assumption). Groups were simulated as a single point. Behavioral changes were simulated by assigning an initial azimuthal orientation drawn from a uniform random distribution between $0^{\circ}$ and $360^{\circ}$ to each source (Table I), and allowing vertical and horizontal rotation about that azimuth. Sources were also assigned a maximum depth from a literature-based distribution (Hastie et al., 2006; Wells et al., 2009), and were allowed to occupy depths between the maximum and sea surface. For group detection purposes, only the most detectable cue in a time window matters; therefore, only the maximum possible received level for each source, given the allowed rotation and depth distribution, was retained.

\section{Other model parameters}

Detection probabilities were estimated for pantropical spotted dolphin as an example of a shallow-diving pelagic delphinid species, and Risso's dolphin as an example of a deep-diving delphinid species. Pantropical spotted dolphins reach 1.6 to $2.5 \mathrm{~m}$ in length at maturity, dive to an average depth of approximately $20 \mathrm{~m}$, with maximum dive depths near $200 \mathrm{~m}$ and on-axis click source levels of $\sim 210 \mathrm{~dB}_{\mathrm{pp}}$ re $1 \mu \mathrm{Pa} @ 1 \mathrm{~m}$ (Perrin and Hohn, 1994; Baird et al., 2001; Perrin, 2001; Au and Herzing, 2003; Scott and Chivers, 2009). Risso's dolphins are larger, with body lengths up to $3.8 \mathrm{~m}$, average dive depths less than $50 \mathrm{~m}$, and maximum dive depths near $500 \mathrm{~m}$ (Wells et al., 2009, though the study involved a single rehabilitated animal released into the wild, and hence these data may not reflect the true dive depth distribution of the species). On-axis source levels for Risso's dolphins are expected to be higher than for shallow-divers, around $220 \mathrm{~dB}_{\mathrm{pp}}$ re $1 \mu \mathrm{Pa} @ 1 \mathrm{~m}$ (Fish and Turl, 1976; Madsen et al., 2004; Smith et al., 2016). Both species execute dives approximately 5 to $10 \mathrm{~min}$ long, and spend more time near the sea surface than deeper diving odontocetes, for instance sperm whales and beaked whales (Scott and Chivers, 2009; Wells et al., 2009; Hildebrand et al., 2015). Log-normal distributions were used to model the depth distributions of both species to capture the skew of depth distributions reported in the literature including both dives and surface intervals. Note that the mean of a log-normal distribution is the mean of the natural logarithm of the distribution (Table I). For example, a log-normal mean of $3 \mathrm{~m}$ translates into a mean depth of $\mathrm{e}^{3}$ or $20.1 \mathrm{~m}$.

Signal peak frequency, which is affected by sound absorption at these high frequencies $(>30 \mathrm{kHz})$, was estimated as the mean of the peak frequencies of the detected clicks for each species from the HARP recordings. Because echolocation click frequency as a function of off-axis angle is unknown, a single frequency value was used to approximate transmission loss, although a more accurate representation of attenuation is a goal for future efforts (Ainslie, 2013). For modeling purposes (both cue- and group-based), the critical value is the mean peak frequency of received clicks. This frequency was identified for each species based on an analyst review of the empirical detection data.

\section{Parameter influence on detection probability}

The influence of each model parameter, $X$, on detection probability was evaluated through 500 model iterations in which $X$ was allowed to vary, while all other variables were held constant at the midpoint of the range considered. After each parameter-specific run, the effect of varying $X$ on detection probability $(P)$ was described by the slope $S$ of a regression line fitting $P$ as a function of $X$ in terms of detection probability $(\%)$ per parameter unit (all relationships were approximately linear over the tested parameter ranges).

To facilitate between-parameter comparisons a Z-score normalization of $X\left(Z_{X}\right)$ was computed as

$$
Z_{X}=X \mu_{X} / \sigma_{X}
$$

where $\mu_{X}$ and $\sigma_{X}$ are the mean and standard deviation of $X$, respectively. The slope $S_{z}$ of the regression line fitting $P$ as a function of $Z_{X}$ provides a unitless estimate of each parameter's effect across the tested range. $\mathrm{R}^{2}$ values were computed for each parameter to measure goodness of fit and the strength of the relationship between each parameter and detectability. 


\section{E. Acoustic propagation modeling}

Transmission loss (TL) associated with propagation of the signals in the environment included geometric spreading and frequency-dependent absorption. TL was simulated as a function of horizontal distance and elevation relative to the sensor using the ray-tracing algorithm Bellhop (Porter and Bucker, 1987), with site-specific environmental and physical parameters drawn from the Oceanographic and Atmospheric Master Library (OAML). TL was simulated for a sensor using the same location and depth of the sensor used in the in situ experiment. Using the theorem of acoustic reciprocity (Rayleigh, 1945), incoherent TL in a gridded volume around the sensor was simulated by defining the sensor as an omnidirectional sound source for computational efficiency (e.g., Helble et al., 2013a).

TL at each frequency was computed along 64 equally spaced radials around the sensor. Each radial calculation resulted in a grid covering the full depth of the water column, and extending $10 \mathrm{~km}$ horizontally from the sensor. Three thousand rays were projected from the sensor position along each radial at launch angles ranging from $0^{\circ}$ to $90^{\circ}$, where $90^{\circ}$ is directly above the instrument. Grid resolution was $1 \mathrm{~m}$ in the vertical plane and $10 \mathrm{~m}$ in the horizontal. In situ detection SLs were estimated using the sonar equation with modeled TL and in situ RL as

$$
\mathrm{SL}=\mathrm{RL}+\mathrm{TL},
$$

where SL is the effective source level, including any effects of beam orientation. The distributions of in situ source levels were compared with the model-predicted source level distributions, which combined on-axis source levels with beamrelated transmission loss (see Sec. II A).

Environmental and physical parameters for the measurement site were extracted from OAML using ESME Workbench (Mountain et al., 2013). Bottom bathymetry was obtained from the global Digital Bathymetry Database (DBDB, version 5.4, $1^{\prime}$ resolution) available from OAML. Bottom composition was clay according to OAML's Bottom Sediment Type database (BST, version 2.0, 2' resolution). The bottom boundary was modeled as an acousto-elastic halfspace (Porter, 1991). A mean monthly sound speed profile for the month of November was drawn from OAML's Generalized Digital Environment Model (GDEM, version 3.0, $15^{\prime}$ resolution). The sound speed profile was based on averages for the month and did not reflect particular hydrographic events. This approach aligns with the aim of the model to provide an average probability of detection over a large number of encounters and a variety of conditions. No sound speed profile was available for the exact location and day of the experiment. However the effect of sound speed profile selection was tested by comparing detection probability predictions calculated using mean profiles from January and July (Frasier, 2015). This analysis did not indicate any significant seasonal differences in detection probabilities for deep or shallow divers, using cue counting or group counting methods.

\section{F. Comparison with in situ recordings}

In situ recordings were made with a tracking HARP using four calibrated hydrophones (Channel Technologies
Group, ITC-1042), positioned in a tetrahedral array with a $1.1 \mathrm{~m}$ maximum aperture (Wiggins and Hildebrand, 2007). The array was suspended $\sim 20 \mathrm{~m}$ above the seafloor on a mooring, so it was possible the array's azimuthal heading, and to a lesser extent its tilt, changed over long periods, depending on near-seafloor currents. Each hydrophone was recorded with a $100 \mathrm{kHz}$ sampling rate over a total deployment duration of $25.5 \mathrm{~h}$. Instrument position and array orientation after settling on the seafloor were estimated by circumnavigating the tracking HARP with the deployment ship while sending $11 \mathrm{kHz}$ interrogation pings from a towed transducer with known global positioning system (GPS) locations (Wiggins et al., 2012).

During the tracking HARP deployment, one 60-min Risso's dolphin encounter and four consecutive presumed pantropical spotted dolphin encounters over a 3-h period were recorded and tracked. Because the array sensor spacing was about $1 \mathrm{~m}$, a click's acoustic travel time between sensors was less than $1 \mathrm{~ms}$ and could be identified on all four hydrophones without confusion with the next or preceding consecutive click (i.e., dolphin inter-click interval $>50 \mathrm{~ms}$ ). Using this configuration, three-dimensional source angles were estimated by finding the least-squares best-fit between the in situ signal time difference of arrivals (TDOAs) between hydrophone pairs and a set of modeled TDOAs precomputed across a grid of source angles defined by azimuth and elevation angle pairs (Wiggins et al., 2012). Elevation angles ranged from $0^{\circ}$ to $90^{\circ}$ (directly above the instrument) and azimuthal angles ranged from $0^{\circ}$ to $359^{\circ}$ in $1^{\circ}$ increments.

Absolute position of the source could not be determined because source depth was unknown; however, for sources near the sea surface, horizontal position was estimated by intersecting the three-dimensional angle ray from the source with the sea surface. For Risso's dolphin (deep divers), a second set of positions were estimated assuming that sources were located at a depth of $100 \mathrm{~m}$. The localization algorithm was verified by acoustically tracking the ship's transducer pings and comparing the acoustically based position estimates to the vessel's GPS coordinates (Wiggins et al., 2012). Transducer ping times were identified by filtering the recordings using a second-order infinite impulse response resonator (IIR) filter with peak frequency of $11 \mathrm{kHz}$ and a $250 \mathrm{~Hz}$ bandwidth (MATLAB DSP Systems Toolbox, Version R2012b). The arrival time of a ping was defined as the moment the filtered signal rose above $110 \mathrm{~dB}_{\mathrm{pp}}$ re $1 \mu \mathrm{Pa}$. TDOAs of the same ping across hydrophone pairs were used to track the vessel.

\section{RESULTS}

\section{A. Model predictions}

\section{Cue-counting model}

Cue-counting model predictions estimated that an average of $3.8 \%$ [coefficient of variation $(\mathrm{CV})=0.42$ ] of shallow diver clicks produced within $5 \mathrm{~km}$ of the sensor would be detected, while an average of $12.3 \%(\mathrm{CV}=0.27)$ of deep diver clicks would be detected (Table II). In the shallow diver case, an average of $93 \%(\mathrm{CV}=0.07)$ of clicks produced within $200 \mathrm{~m}$ of the sensor were detectable, and 
TABLE II. Mean predicted detection rates $(\%)$ and standard deviations $(\sigma)$ predicted by each model within a $5 \mathrm{~km}$ radius circular area around the HARP site. Estimates are based on 500 model iterations for deep and shallow divers, respectively.

\begin{tabular}{lcc}
\hline \hline Model & Shallow & Deep \\
\hline Click & $3.8 \pm 1.6 \sigma$ & $12.3 \pm 3.3 \sigma$ \\
Group & $14.0 \pm 5.1 \sigma$ & $44.1 \pm 9.0 \sigma$ \\
\hline
\end{tabular}

detectability decreased monotonically with range [Fig. 1(A)]. Detectability fell steeply for shallow diver clicks at ranges between 0.5 and $1.5 \mathrm{~km}$. Less than $2 \%$ of the shallow diver clicks produced more than $2 \mathrm{~km}$ from the sensor were detectable [Fig. 1(A)].

On average, $100 \%(\mathrm{CV}=0.00)$ of simulated deep diver clicks produced within $200 \mathrm{~m}$ (horizontal range) of the sensor, and over $97 \%$ of clicks produced within $1 \mathrm{~km}$ of the sensor, were detectable [Fig. 1(B)]. Deep diver click detection probabilities dropped off rapidly between 1.5 and $2 \mathrm{~km}$ from the instrument. Less than $3 \%$ of deep diver clicks produced more than $3 \mathrm{~km}$ from the sensor were detectable.

Detection probabilities predicted by the cue counting model were most heavily influenced by the parameter choice of mean source level (Table III). A $1 \mathrm{~dB}_{\mathrm{pp}}$ re $1 \mu \mathrm{Pa} @ 1 \mathrm{~m}$ increase in mean source level for shallow divers increased mean detection probability by $0.54 \%$, for example, mean detectability rose to $3.8 \%+0.54 \%=4.3 \%\left(\mathrm{R}^{2}=0.97\right)$. Pitch angle was also predicted to influence mean detection probabilities. A $1^{\circ}$ increase in the standard deviation of pitch led to a $0.05 \%$ increase in mean detectability $\left(\mathrm{R}^{2}=0.65\right)$. Beam directivity and off-axis amplitude were inversely related to detectability. A $1 \mathrm{~dB}$ increase in mean directivity for shallow divers decreased mean predicted detectability by $0.25 \%$ $\left(\mathrm{R}^{2}=0.67\right)$, while a $1 \mathrm{~dB}$ increase in off-axis transmission
TABLE III. Influence of model input parameters on click detection probability. For each input parameter in the model a set of 500 model iterations were run holding all other variables constant, and allowing only the variable of interest to change. The effect of the variable of interest on detection probability is reported in two ways: (1) as a slope $(S)$ in percent per unit increase in the each parameter, and (2) as a slope $S_{Z}$ in percent per Z-score normalized unit increase in each parameter. $\mathrm{R}^{2}$ values indicate how well each regression line fits the data, with values near one indicating a close fit.

\begin{tabular}{lcccccccc}
\hline \hline & \multicolumn{3}{c}{ Shallow } & & \multicolumn{3}{c}{ Deep } \\
\cline { 2 - 5 } \cline { 7 - 9 } Parameter & $\mathrm{S}(\%)$ & $S_{Z}(\%)$ & $\mathrm{R}^{2}$ & & $\mathrm{~S}(\%)$ & $S_{Z}(\%)$ & $\mathrm{R}^{2}$ \\
\hline Cue-Counting Model & & & & & & \\
Mean Source Level & $0.54 / \mathrm{dB}$ & 1.53 & 0.97 & & $1.15 / \mathrm{dB}$ & 3.24 & 0.98 \\
Directivity & $-0.25 / \mathrm{dB}$ & -0.29 & 0.67 & & $-0.46 / \mathrm{dB}$ & -0.54 & 0.70 \\
Pitch Standard & $0.05 / \mathrm{deg}$ & 0.27 & 0.65 & & $0.07 / \mathrm{deg}$ & 0.36 & 0.52 \\
Deviation & & & & & & \\
Dive Depth & $0.07 / \mathrm{m}$ & 0.03 & 0.02 & & $0.16 / \mathrm{m}$ & 0.07 & 0.04 \\
Mean 90 TL & $-0.21 / \mathrm{dB}$ & -0.12 & 0.30 & & $-0.49 / \mathrm{dB}$ & -0.28 & 0.35 \\
Mean $180^{\circ} \mathrm{TL}$ & $-0.12 / \mathrm{dB}$ & -0.07 & 0.11 & & $-0.28 / \mathrm{dB}$ & -0.16 & 0.16 \\
Group-Counting & & & & & & \\
Model & & & & & & \\
Mean Source Level & $1.72 / \mathrm{dB}$ & 4.94 & 0.99 & & $2.85 / \mathrm{dB}$ & 7.86 & 0.99 \\
Yaw: Mean Rotation & $0.09 / \mathrm{deg}$ & 1.23 & 0.91 & & $0.30 / \mathrm{deg}$ & 3.98 & 0.98 \\
Maximum Dive Depth & $0.25 / \mathrm{m}$ & 0.07 & 0.03 & & $1.11 / \mathrm{m}$ & 0.31 & 0.22 \\
Pitch: Mean Rotation & $0.91 / \mathrm{deg}$ & 5.17 & 0.95 & & $0.63 / \mathrm{deg}$ & 3.69 & 0.71 \\
Minimum Off-Axis TL & $-0.57 / \mathrm{dB}$ & -0.67 & 0.73 & & $-0.55 / \mathrm{dB}$ & -0.63 & 0.54 \\
\hline \hline
\end{tabular}

loss at $90^{\circ}$ decreased detectability by $0.21 \%\left(\mathrm{R}^{2}=0.30\right)$. Dive depth and transmission loss at $180^{\circ}$ (i.e., sound transmission from the tail-end of the animal) were only weakly correlated with mean detection probability $\left(\mathrm{R}^{2}=0.02\right.$ and 0.11 , respectively). Z-score normalized slopes indicated $\mathrm{SL}$ had the highest impact on click detectability $\left(S_{z}=1.53 \%\right)$. Directivity and pitch were also influential $\left(S_{z}=-0.29 \%\right.$ and $S_{z}=0.27 \%$, respectively).
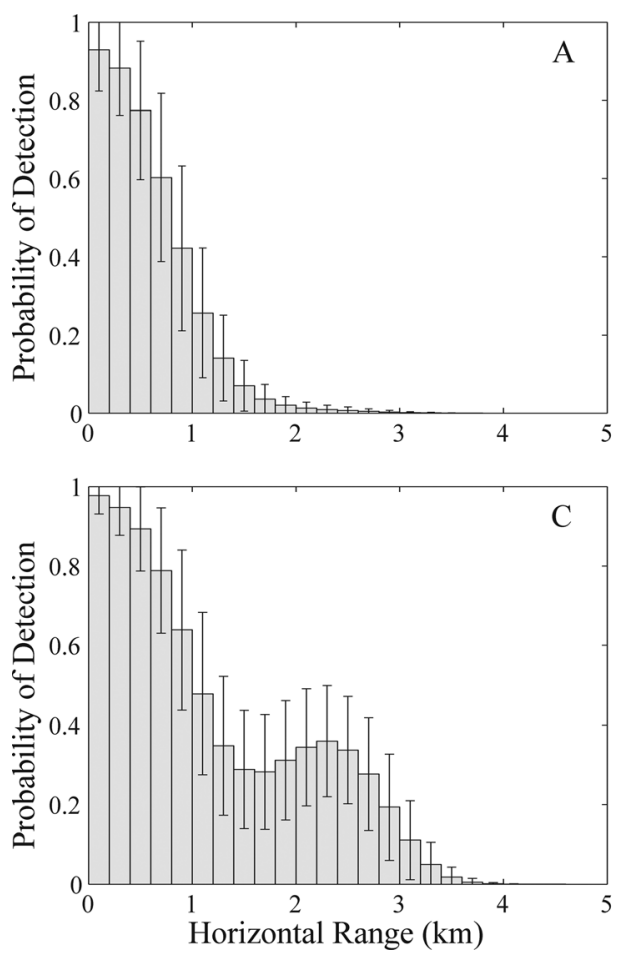

J. Acoust. Soc. Am. 140 (3), September 2016
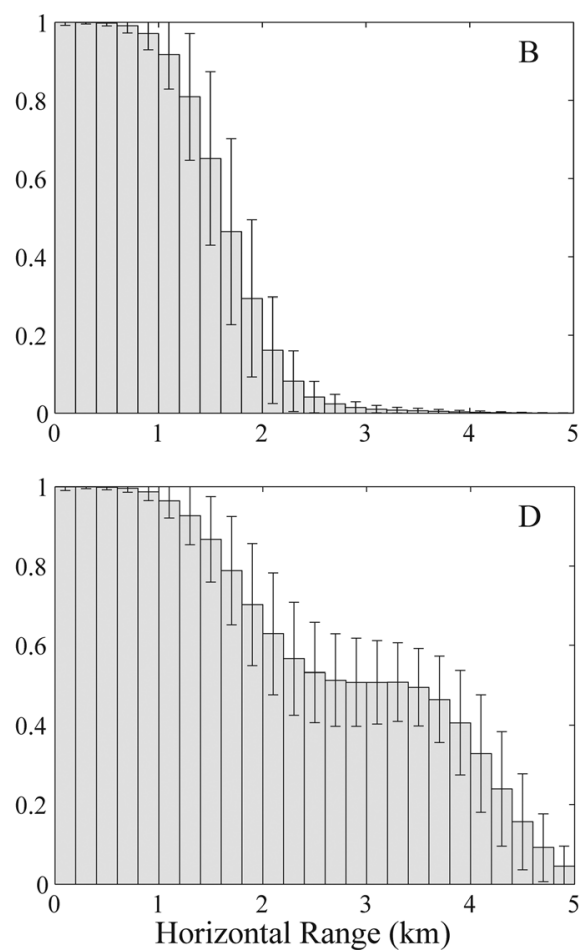

FIG. 1. Modeled detection probability as a function of range. Each bar represents detection probability in a $200 \mathrm{~m}$ range bin. Error bars indicate 1 standard deviation from the mean. (A) Cue-based model probability of detecting a shallow diver click. (B) Cuebased model probability of detecting a deep diver click. (C) Group-based model probability of detecting a clicking group of shallow divers during a 5min interval. (D) Group-based model probability of detecting a clicking group of deep divers during a 5-min interval. 
The deep diver cue-based model predictions responded similarly to parameter variations, but the percent changes relative to mean detection probability were larger (Table III). For instance, a $1 \mathrm{~dB}$ increase in detectability in average deep diver source level led to a $1.15 \%$ increase in mean detectability, while a $1 \mathrm{~dB}$ increase in directivity led to a $0.46 \%$ decrease.

\section{Group-counting model}

The group-counting model estimated that shallow diving groups within $5 \mathrm{~km}$ of the sensor would be detected in an average of $14.0 \%(\mathrm{CV}=0.36)$ of 5 -min windows, while deep diving groups would be detected in $44.1 \%(\mathrm{CV}=0.20)$ of windows (Table II). Simulated shallow diver groups were detectable in over $63 \%$ of time windows on average when located within $1 \mathrm{~km}$ horizontal range of the sensor. Detection probabilities fell below $2 \%$ beyond $3.5 \mathrm{~km}$ [Fig. 1(C)]. Detection probabilities dipped to an average of $28 \%$ at a horizontal range of $1.5 \mathrm{~km}$ and then increased slightly at $2.5 \mathrm{~km}$. Deep diver groups were detectable in over $98 \%$ of time windows on average when located within $1 \mathrm{~km}$ of the sensor. Detection probabilities were around 50\% between 2 and $4 \mathrm{~km}$, and decreased steadily thereafter for the deep diver groups [Fig. 1(D)].

The group model detection probabilities were most heavily influenced by mean source level (Table III). For shallow and deep divers, a $1 \mathrm{~dB}$ increase in mean source level led to $1.72 \%$ and $2.85 \%$ increases in mean detection probability, respectively $\left(\mathrm{R}^{2}=0.99\right.$ for both). Mean group rotation in the vertical plane also had an effect on detection probabilities with a $1^{\circ}$ increase in pitch angle rotation increased detection probabilities by $0.91 \%$ and $0.63 \%$ for shallow and deep divers, respectively $\left(\mathrm{R}^{2}=0.95\right.$ and 0.71$)$. The effect of horizontal rotation was smaller, at $0.09 \%$ and $0.30 \%$, respectively $\left(\mathrm{R}^{2}=0.91\right.$ and 0.98$)$. Off-axis transmission loss was inversely correlated with detectability, while all other input variables were positively correlated with detectability. Maximum dive depth was only weakly correlated with detectability for shallow and deep diving groups $\left(R^{2}=0.03\right.$ and 0.22 , respectively). Z-score normalized slopes indicated that SL had the highest impact on click detectability for both shallow and deep divers $\left(S_{z}=4.94 \%\right.$ and $7.86 \%$, respectively). Rotation in both the vertical and horizontal planes were also influential.

\section{B. In situ encounters compared to models}

\section{Vessel tracking}

Vessel position estimates calculated using the TDOA minimization scheme agreed with the vessel's GPS coordinates (Fig. 2). Azimuthal estimates deviated from expected values based on GPS vessel position during the first part of the circumnavigation period, but matched closely for the second half of that period. This may be attributed to rotations of the tetrahedral sensor frame during the first part of the tracking period since the array is non-stationary and attached to a mooring line. Localization-based horizontal distances

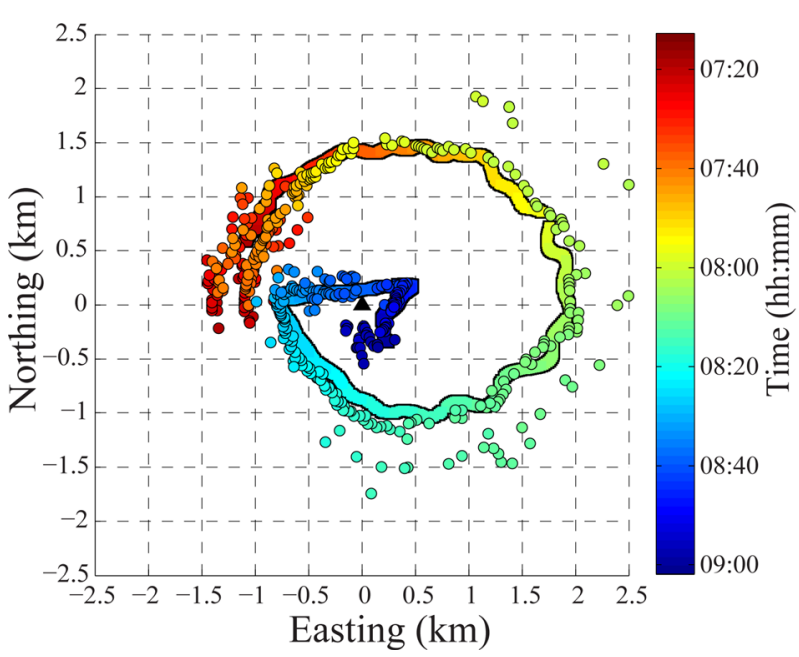

FIG. 2. (Color online) Ship position estimates (circles) from localizations using time difference of arrivals (TDOAs) of transducer pings from the ship at known GPS locations recorded on a four-sensor tracking HARP (black triangle at 0,0 ). Colored line indicates true ship position based on GPS locations. Color indicates the time associated with each position, in GMT, with red indicating the beginning of the vessel tracking period, and blue indicating the end of the tracking period. Local time is GMT - 05:00.

between the HARP and ship were comparable with expected ranges based on ship GPS positions.

\section{Risso's dolphin encounter}

A total of 3866 Risso's dolphin echolocation clicks were localized using the tracking HARP recording, during a 1-h encounter (Fig. 3). Most of the detections were obtained during the first two-thirds of this period, prior to the closest point of approach (CPA) at 06:50 Greenwich Mean Time (GMT), when the animals were moving from east to west over the instrument [Figs. 3, 4(A), and 4(B)]. Sound pressure received levels increased as the animals approached the instrument [Fig. 4(C)], but estimated maximum sound

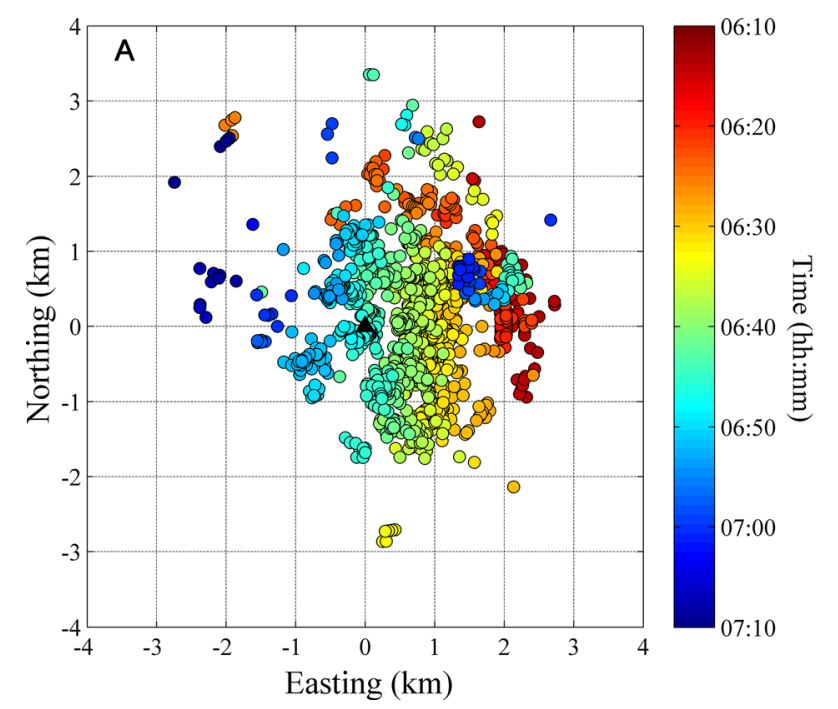

FIG. 3. (Color online) Map view of echolocation click localizations of Risso's dolphins. The black triangle represents the tracking HARP location at $(0,0)$. Each colored dot indicates the location of a single click, assuming the click was produced near the sea surface, with color indicating the time at which the click was detected in GMT (local time is GMT - 05:00). 

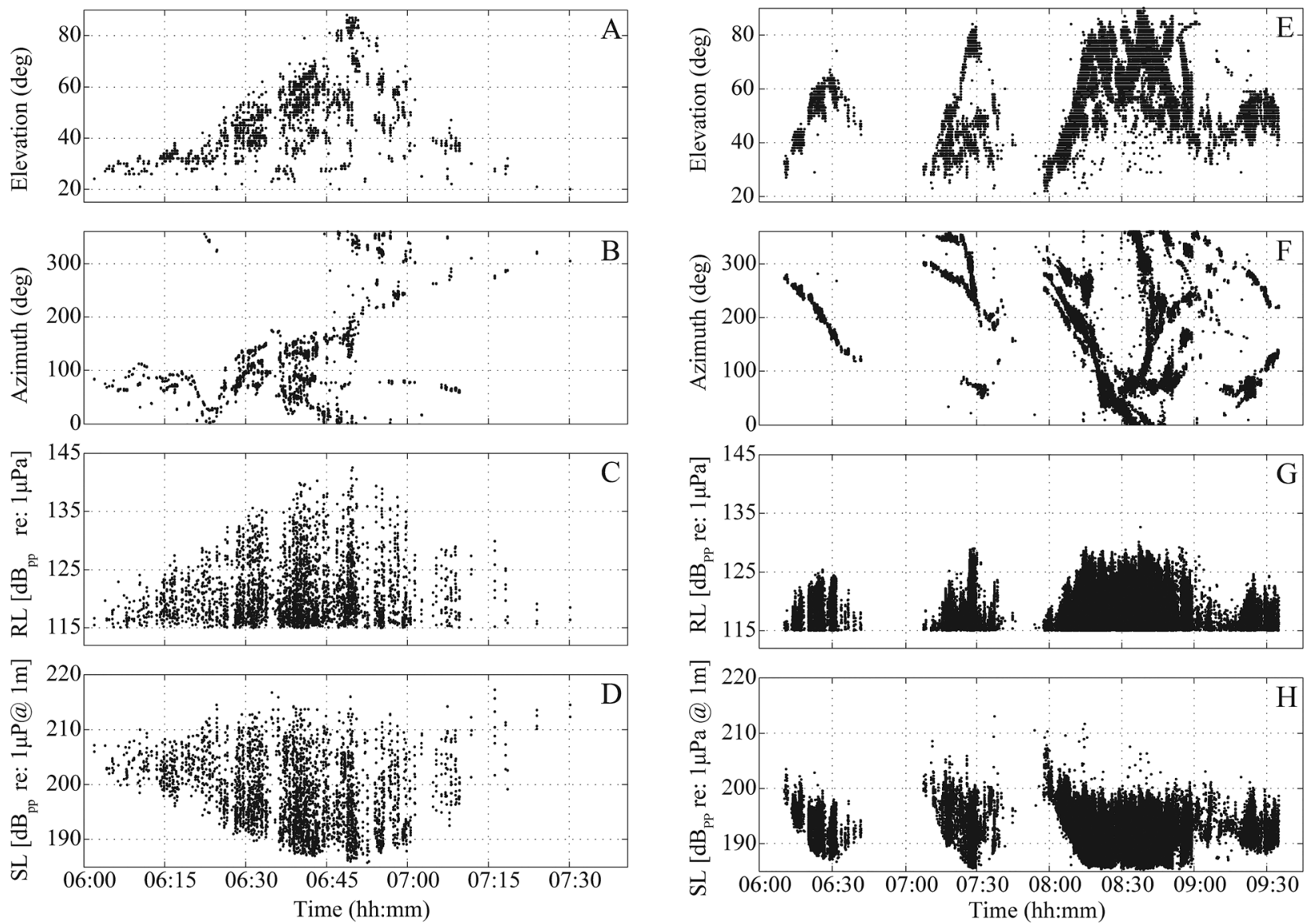

FIG. 4. Time series of localized delphinid encounters (left: Risso's dolphin; right: Pantropical spotted dolphin). Each black dot represents one localized echolocation click. [(A) and (E)] Elevation angle of localized echolocation clicks relative to the HARP, where 90 is directly overhead. [(B) and (F)] Azimuthal angle of localized clicks relative to the HARP. [(C) and (G)] Received level of localized echolocation clicks. [(D) and (H)] Estimated source level of localized echolocation clicks.

pressure source levels did not [Fig. 4(D)]. Clicks with lower estimated SLs became detectable as the animals approached the instrument.

The Risso's dolphin encounter consisted of a small group of animals with a non-uniform distribution in space. Fewer clicks were detected between $25^{\circ}$ and $45^{\circ}$ elevation angle than expected if animals were uniformly distributed around the sensor [Fig. 5(A)].

Clicks were localized at a maximum horizontal range of $3.4 \mathrm{~km}$ (Table IV). The maximum detection range predicted by the cue-counting model was $4.1 \mathrm{~km}(\mathrm{CV}=0.13)$. Mean detection range in situ $(1.3 \mathrm{~km})$ was slightly lower than that predicted by the cue-counting model $(1.4 \mathrm{~km})$; however, CVs were large for both values $(0.52$ and 0.12 , respectively; Table IV). In situ received levels reached a maximum of 143 $\mathrm{dB}_{\mathrm{pp}}$ re $1 \mu \mathrm{Pa}$ with most received clicks much lower in amplitude [Table IV, Fig. 4(C)]. The modeled maximum RL was only slightly higher, at $144 \mathrm{~dB}_{\mathrm{pp}}$ re $1 \mu \mathrm{Pa}(\mathrm{CV}=0.03)$. Mean in situ and cue-counting model RLs were also similar at 121 and $123 \mathrm{~dB}_{\mathrm{pp}}$ re $1 \mu \mathrm{Pa}$, respectively $(\mathrm{CVs}=0.04$ and $0.01)$.

The in situ source level distribution was broader than the distribution predicted by the cue-counting model [Fig. 6(C)]; however, the model predicted more extreme maximum and minimum SLs. The maximum in situ SL estimate was 217 $\mathrm{dB}_{\mathrm{pp}}$ re $1 \mu \mathrm{Pa} @ 1 \mathrm{~m}$, considerably lower than the theoretical maximum of $230 \mathrm{~dB}_{\mathrm{pp}}$ re $1 \mu \mathrm{Pa} @ 1 \mathrm{~m}(\mathrm{CV}=0.03)$ predicted by the cue-counting model (Table IV). The minimum in situ source level estimate and model prediction were similar at 186 and $185 \mathrm{~dB}_{\mathrm{pp}}$ re $1 \mu \mathrm{Pa} @ 1 \mathrm{~m}(\mathrm{CV}=0.02)$, respectively. Mean SL in situ was $198 \mathrm{~dB}_{\mathrm{pp}}$ re $1 \mu \mathrm{Pa} @ 1 \mathrm{~m}(\mathrm{CV}=0.03)$ compared to a model predicted mean of $200 \mathrm{~dB}_{\mathrm{pp}}$ re $1 \mu \mathrm{Pa} @$ $1 \mathrm{~m}(\mathrm{CV}=0.02)$ [Table IV, Fig. 6(C)]. Assuming that animals were located at a depth of $100 \mathrm{~m}$ rather than at the sea surface reduced the mean in situ horizontal detection range to $1.1 \mathrm{~km}$ $(\mathrm{CV}=0.52)$. Mean SL also decreased to $196 \mathrm{~dB}_{\mathrm{pp}}$ re $1 \mu \mathrm{Pa} @$ $1 \mathrm{~m}(\mathrm{CV}=0.03)$.

\section{Pantropical spotted dolphin encounters}

Four successive encounters with presumed pantropical spotted dolphins were tracked over a 4-h period [Figs. $4(\mathrm{E})-4(\mathrm{H}), 7]$, with a total of 62955 clicks localized. The first, second, and fourth encounters appear to be relatively small groups of animals, while the third pass consisted of many overlapping tracks and presumably a larger number of animals (Figs. 4 and 7). RLs reached the highest levels during the third pass, between 08:30 and 09:00 GMT when the animals were at the CPA [Fig. 4(E) and 4(G)]. Estimated source levels were highest at the beginning of each pass, as the animals approached the instrument from a distance [Fig. 4(H)]. 

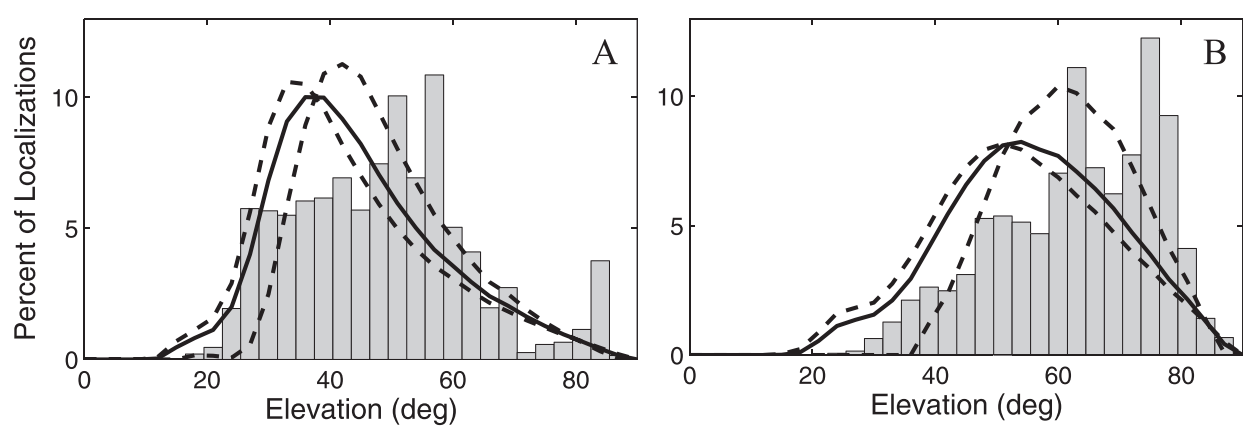

FIG. 5. Comparison of elevation angles at which echolocation clicks were localized in situ (gray bars) and from model predictions (black lines) assuming that animals have a uniform random distribution in the horizontal plane around the hydrophone. Solid black line indicates model-predicted mean; dotted lines represent \pm 1 standard deviation from the mean. In (A), Risso's dolphin clicks are localized in situ at approximately the elevation angles predicted by the model, with slightly fewer detections than expected between $20^{\circ}$ and $45^{\circ}$, and more detections than expected at larger elevation angles. In (B) pantropical spotted dolphin echolocation clicks are localized at larger elevation angles than predicted by the model mean, with fewer animals at angles less than $35^{\circ}$. Mismatches suggest that clicking animals were not uniformly distributed.

Pantropical spotted dolphin clicks were localized in situ at a maximum horizontal range of $3.2 \mathrm{~km}$, while the cuecounting model predicted a maximum detection range of $2.7 \mathrm{~km}(\mathrm{CV}=0.22$; Table IV). Over $95 \%$ of in situ localizations fell within $2 \mathrm{~km}$ of the sensor [Fig. 6(G)]. Mean horizontal detection range in situ was $0.6 \mathrm{~km}(\mathrm{CV}=0.67)$ while the cue counting model predicted a slightly higher mean of $0.8 \mathrm{~km}(\mathrm{CV}=0.17)$. Mean $\mathrm{RL}$ was similar between the model and in situ localizations 119 and $120 \mathrm{~dB}_{\mathrm{pp}}$ re $1 \mu \mathrm{Pa}$, respectively [Fig. 6(H)], with a maximum RL of $133 \mathrm{~dB}_{\mathrm{pp}}$ re $1 \mu \mathrm{Pa}$ in both cases. The SL distribution from the in situ data was skewed higher and had fewer extreme values than predicted by the model results [Fig. 6(I)]. The mean SLs were the same in situ and in model predictions: $192 \mathrm{~dB}_{\mathrm{pp}}$, re $1 \mu \mathrm{Pa}$ (a $1 \mathrm{~m}$ with $\mathrm{CVs}$ of 0.01 and 0.02 , respectively. Modeled

TABLE IV. Comparison of modeled and in situ parameter distributions for cue-based model. The model distributions for RL, SL, and HR are based on 500 model iterations. Subscripts indicate HARP data assuming animals are located at the surface (H0), HARP data assuming animals are at $100 \mathrm{~m}$ (H100), and cue-based model values (M). In situ RL distributions do not depend on depth; therefore, the subscript $\mathrm{H}$ is used. CVs are reported in parentheses. RL amplitudes are in $\mathrm{dB}_{\mathrm{pp}}$ re: $1 \mu \mathrm{Pa}$ and SL amplitudes are in $\mathrm{dB}_{\mathrm{pp}}$ re: $1 \mu \mathrm{Pa} @ 1 \mathrm{~m}$.

\begin{tabular}{lcccccccc}
\hline \hline & \multicolumn{2}{c}{ Deep diver (Risso's) } & & \multicolumn{2}{c}{ Shallow diver (Pantropical) } \\
\cline { 2 - 3 } \cline { 7 - 8 } Parameter & Mean & Max & Min & & Mean & Max & Min \\
\hline $\mathrm{RL}_{\mathrm{H}}(\mathrm{dB})$ & 121 & 143 & 115 & & 119 & 133 & 115 \\
& $(0.04)$ & & & & $(0.03)$ & & \\
$\mathrm{RL}_{\mathrm{M}}(\mathrm{dB})$ & 123 & 143 & 115 & & 120 & 133 & 115 \\
& $(0.01)$ & $(0.03)$ & $(0.00)$ & & $(0.01)$ & $(0.03)$ & $(0.00)$ \\
$\mathrm{SL}_{\mathrm{H} 0}(\mathrm{~dB})$ & 198 & 217 & 186 & & $192(0.02)$ & 213 & 185 \\
& $(0.03)$ & & & & & & \\
$\mathrm{SL}_{\mathrm{H} 100}(\mathrm{~dB})$ & 196 & 215 & 184 & & - & - & - \\
& $(0.03)$ & & & & & & \\
$\mathrm{SL}_{\mathrm{M}}(\mathrm{dB})$ & 200 & 228 & 185 & & 192 & 216 & 179 \\
& $(0.02)$ & $(0.03)$ & $(0.02)$ & & $(0.01)$ & $(0.04)$ & $(0.01)$ \\
$\mathrm{HR}_{\mathrm{H} 0}(\mathrm{~km})$ & 1.2 & 3.4 & 0.0 & & 0.6 & 3.2 & 0.0 \\
& $(0.52)$ & & & & $(0.67)$ & & \\
$\mathrm{HR}_{\mathrm{H} 100}(\mathrm{~km})$ & 1.1 & 3.1 & 0.0 & & - & - & - \\
$\mathrm{HR}_{\mathrm{M}}(\mathrm{km})$ & $(0.52)$ & & & & & \\
& 1.3 & 4.1 & 0.1 & & 0.8 & 2.7 & 0.0 \\
& $(0.13)$ & $(0.16)$ & $(0.52)$ & $(0.17)$ & $(0.22)$ & $(0.50)$ \\
\hline \hline
\end{tabular}

minimum and maximum SLs were $179 \mathrm{~dB}_{\mathrm{pp}}$ re $1 \mu \mathrm{Pa} @ 1 \mathrm{~m}$ $(\mathrm{CV}=0.01)$ and $216 \mathrm{~dB}_{\mathrm{pp}}$ re $1 \mu \mathrm{Pa} @ 1 \mathrm{~m}(\mathrm{CV}=0.04)$, respectively, while the in situ minimum and maximum were less extreme, at 185 and $213 \mathrm{~dB}_{\mathrm{pp}}$, re $1 \mu \mathrm{Pa} @ 1 \mathrm{~m}$.

The distribution of elevation angles of localized clicks during the pantropical spotted dolphin encounter differs from that predicted for a uniform randomly distributed set of
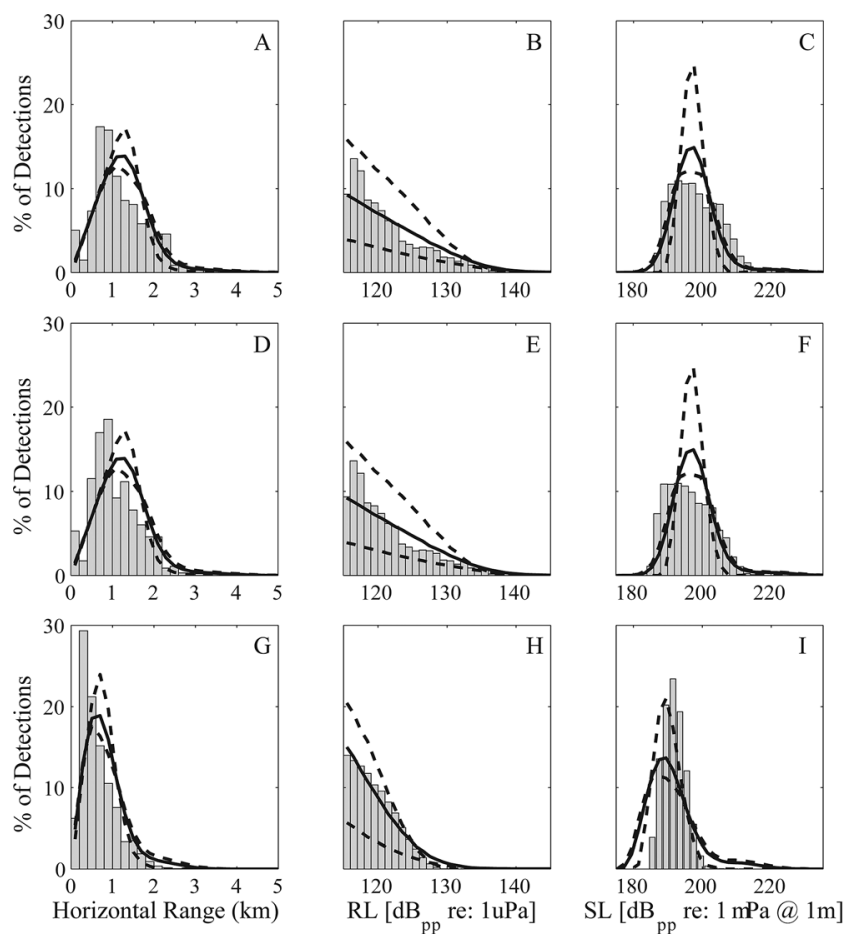

FIG. 6. Comparison of in situ data (gray bars) with cue-counting model predicted output (black lines). Solid black lines represent mean model prediction, with dotted lines representing \pm 1 standard deviation from the mean. Top [(A)-(C)]: Risso's dolphin encounter assuming animals at the surface; Center [(D)-(F)]: Risso's dolphin encounter assuming animals at $100 \mathrm{~m}$ depth; Bottom [(G)-(I)]: Pantropical spotted dolphin encounter assuming animals at surface. Plots from left to right show horizontal range, received level (RL), and source level (SL). Models are designed to predict averages over many encounters; therefore, perfect agreement with in situ data is not expected given the small number of encounters. More precise input parameter estimates describing click characteristics and animal behavior would decrease uncertainty in the model predictions. 

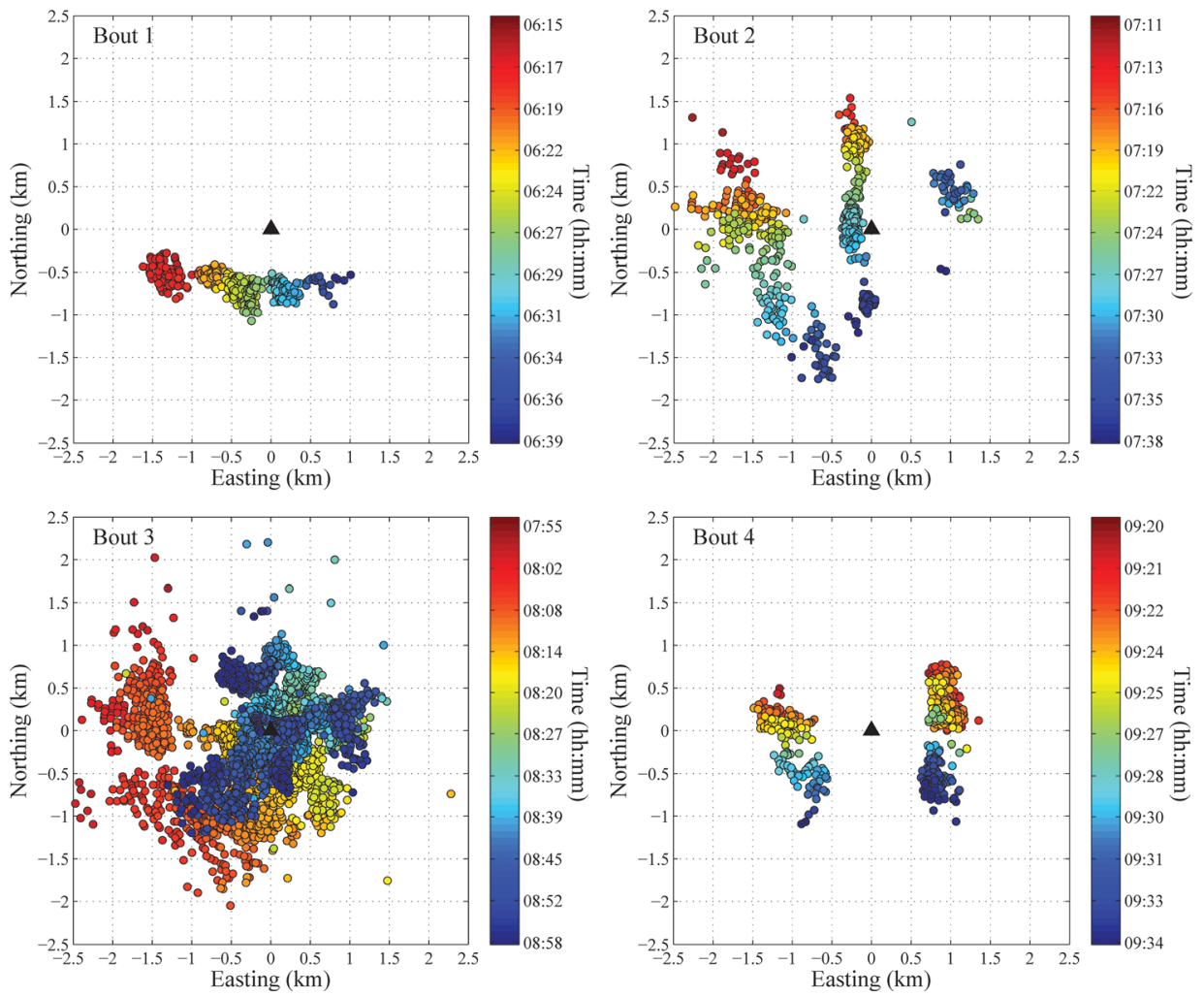

FIG. 7. (Color online) Map view of echolocation click localizations during four consecutive presumed pantropical spotted dolphin encounters. The black triangle represents the tracking HARP location at $(0,0)$. Each colored dot indicates the location of a single click, assuming the click was produced near the sea surface, with color indicating the time at which the click was detected in GMT (Local time is GMT 05:00). Note that the temporal scales differ between plots. sources [Fig. 5(B)], although the two distributions have similar overall shapes. The majority of in situ localizations occurred at an elevation of $50^{\circ}$ or greater, where $90^{\circ}$ indicates that the click was produced directly above the sensor. Fewer clicks than expected were localized at elevations below $50^{\circ}$, although the shape of the in situ distribution fits within 1 standard deviation from the mean distribution predicted by the model. The in situ distribution has a tail of localizations with elevation angles extending to approximately $30^{\circ}$. The cue-counting model predicted elevation angles as low as $20^{\circ}$, however these were not seen in situ.

\section{DISCUSSION}

\section{A. Model predictions}

Received sound pressure received level was used as the metric of detectability in this model, but this is an oversimplification of how most click detectors work. Echolocation click detectability is also influenced by frequency content and energy distribution in the sound pressure time-series, both of which can vary as a function of beam angle. Methods for modeling the effects of beam angle on received click spectraltemporal structure are currently unavailable. For this reason, an alternative approach was used in which click detection was simplified to rely as much as possible on received level, which can be modeled using existing techniques. Unless a click detector has been developed specifically with density estimation in mind, its behavior likely would be too complex to predict using this simplified algorithm. Future work may seek to improve echolocation click simulation to allow for more sophisticated detection methods and more refined estimates of click detectability.
For simulation purposes, animals were assumed to be uniformly distributed in the horizontal plane in the monitored area, on average, across a large number of encounters. At this site, no bathymetric or other persistent features within detection range were expected to influence animal distributions, which were expected to be uniform over the area. However, non-uniform animal distributions could be incorporated into the simulation framework if a more complex spatial distribution was supported by additional studies.

\section{B. Click detection probabilities}

The cue-based detection probability model aims to estimate the likelihood of detecting a single delphinid click produced within a defined area around the sensor. Detection probabilities were high in the small region immediately around the sensor, but were outweighed by low detection probabilities at large ranges, resulting in a low overall detection probability within a $5 \mathrm{~km}$ radius. Since the area monitored increases with the square of distance, the overall probability of detection is low (Table IV).

Cue-based models are sensitive to assumptions about click characteristics. Source level, off-axis amplitude at $90^{\circ}$, and beam directivity strongly affected detectability predictions. Small changes in these input parameters had large effects on overall detectability predictions. The vast majority of detected clicks were predicted to be received off-axis, and the similarities between predicted and in situ RLs and distributions suggest that this was true in the recordings. A more detailed understanding of off-axis RLs in free-ranging delphinids, and RL variability is critical for improving the accuracy of the model predictions. 
Animal body orientation in the vertical plane also affected detectability predictions. If animals rarely click at a steep declination angle, then clicks produced directly above a sensor would be primarily off-axis, and therefore, less detectable, while clicks produced at a distance from the sensor would be on-axis more often, and therefore, more detectable. This may partially explain the pantropical spotted dolphin encounters, where SL was highest when the animals were distant and approaching [Fig. 4(H)]. This effect of distance on SL was not observed in the Risso's dolphin case [Fig. 4(D)], perhaps because their deeper dives led to a higher probability of downward clicking.

Dive depth had only a small effect on predicted detectability; however, the effect would likely increase in cases where dive depths are large relative to the sensor depth.

Many parameters including body orientation, dive depth, and directivity likely vary depending on behavioral state (Jensen et al., 2015). For instance, greater body inclination and dive depth may occur during foraging behaviors compared to traveling behaviors. Development of a multistate model (e.g., Hildebrand et al., 2015, for beaked whales) might account for the effects of behavior on detectability and increase the accuracy of detectability predictions.

\section{Group detection probabilities}

The group-based detection probability model estimates the probability of detecting a group of animals during a specified time window. Integration over the time window is predicted to increase detection probabilities relative to cue counting methods if the window is sufficiently long. The group model estimated the probability of detecting a delphinid group in a 5-min window to be over three times higher than the probability of detecting a single click from that group.

Because it integrates detectability across a time window, the group model predicts larger maximum detection ranges than the click model, given the same conditions. This is because an on-axis click is theoretically detectable at relatively large ranges, but the probability of an individual click being on-axis is very low. In the group model, the probability of a click being on-axis was much higher because the duration of the window and the presence of multiple animals make it more likely that at least one animal in the group was oriented toward the sensor at least once during the time window. While this was probably the case in the recordings, in the model, the distribution of rotational angles and depths expected of an average group was poorly constrained. This is a considerable weakness in the group model because group rotation assumptions have a large effect on detectability predictions.

Increased detection probabilities at larger horizontal ranges may make group model predictions more sensitive to seasonal changes in sound-speed profiles than cue-based model predictions. A small increase in detectability at large ranges will result in a relatively large increase in detection probability, because the area monitored increases with the square of the detection range (Thomas et al., 2010).

Modeling group behavior over a time window requires assumptions about how a group's orientation changes over time. On the basis of a manual review of these encounters and encounters from other sites in the GOM (e.g., Frasier, 2015), the period during which a group of animals appears to be approaching the sensor (RLs steadily increasing over time) is generally much longer than the period during which the group appears to be leaving it (RLs steadily decreasing). This suggests that the animals in a group are more likely to be clicking in their direction of travel, and may not turn back $180^{\circ}$ to click on-axis after CPA. In the case where the animals are foraging, a full $360^{\circ}$ rotation in the time window may be more likely than in a traveling mode. These different behavioral modes are not currently captured by the group model, but their incorporation, along with additional data, could improve the accuracy of the group-based approach.

Group spread in the horizontal plane was not incorporated into the model, because little is known about its relation to group size and behavior. The effect of modeling a group as a single point is shown for short ranges in Fig. $1(\mathrm{C})$, where a dip in detectability is seen at approximately $1.5 \mathrm{~km}$. Incorporating spread could smooth out dips in detectability as a function of range. Average predicted group detectability over the detection area is not expected to change if group spread is incorporated, because the groups are already assumed to be uniform and randomly distributed on average. As a result, increasing group spread is not expected to change the distribution of distances to the most detectable animal in a group. However, if the distribution assumption is incorrect at this site, then spread could significantly influence group detection probabilities. Group movement within the snapshot period is another possible (though non-trivial) extension to the simulation. Animal movement can cause bias in detection probability estimates and this is an active area of research (e.g., Glennie et al., 2015).

In practice, the probability of detecting a group is expected to increase as a function of the number of clicks produced per time window. However, the cue rate and group size information needed to test the effect of clicks produced on probability of detection is currently lacking.

\section{Propagation model}

The modeled sound propagation environment used in these models was generalized based on average monthly conditions at the site, and did not account for the effects of extreme oceanographic events on detectability. In general, the smaller the predicted detection range of the cue, the smaller the impact of sound speed profiles on detectability. Preliminary model exploration indicated no significant effect of annual sound speed profile changes on click detectability.

There are a number of caveats to consider when interpreting the results of the ray-tracing propagation model. First, the ray tracing used did not take phase into account; therefore, it does not predict interference or refraction. Bellhop also has known problems with modeling sea surface boundaries (Porter and Liu, 1994). Although sea surface roughness was included in the propagation model, this captures only small scale features, not the constantly changing swell and surf. In general, indirect delphinid click arrivals were not expected to be detectable at deep sites, and multiple arrivals of the same click are rarely observed. However, 
multiple arrivals are common at shallower sites, therefore poor handling of the surface boundary may have a larger effect at shallow sites.

\section{E. Ground truth}

Localized animals were assumed to be at the surface; however, a subset of clicks may have been produced at depth. Depth estimation would require additional clock-synchronized acoustic recorders, potentially near the sea surface. Clicks produced at depth would be closer to the sensor than those estimated assuming a surface location, reducing some of the estimated horizontal ranges for these encounters. At this site, the effect of assuming that Risso's dolphin were vocalizing at $100 \mathrm{~m}$ rather than at the sea surface was small because sensor depth was large relative to dive depth. At shallower sites, or for deeper divers such as beaked and sperm whales, dive depth is expected to have a larger effect (e.g., Hildebrand et al., 2015).

The method used for estimating source positions assumes that the sound travels from source to receiver along a linear path. In reality, the arrival path is slightly bent by interaction with the thermocline (i.e., refraction; Urick, 1967). At horizontal ranges less than or close to the water depth, the effect of this bending on position estimates was small, as can be seen in the ship localization case. When the ship was close to the sensor, errors were small. As the horizontal distance increased, the error resulting from the linear path assumption also increased. Low elevation angles associated with large horizontal ranges can be problematic as cosine-based range estimates respond non-linearly to small errors in angle estimates. In the case of dolphin detection, ranges are relatively short, and errors due to signal path curvature are estimated to be less than $10 \mathrm{~m}$.

SL estimates from the in situ recordings were below the model-predicted maximum SLs for both species (Table IV). This is likely linked to the low probability of receiving an onaxis click. It is possible that none of the received clicks from the Risso's dolphin encounter were on-axis given the small sample size. As predicted by the model, in situ SLs increased slightly with increasing range, particularly when the animals were approaching the instrument. Further refining SL estimates will likely require an array of multi-sensor recorders capable of resolving source depth, and concurrent tagged, clicking animals.

Both cue and group-based models were designed to simulate average detectability over a large number of encounters and a variety of conditions. A longer in situ time series would be necessary to ground truth the group-based model, and would also increase the strength the of cue-based model to in situ data comparison. Nonetheless, localizations from the in situ data were consistent with the model predictions and support the use of models to estimate detection probabilities for delphinid density estimation. The model framework described can be updated as more refined parameter estimates become available.

The next step in this work will be to refine estimates of key variables including click production rate and group size which are needed to convert detection counts into density estimates using modeled detection probabilities. The following example is provided for illustrative purposes only: In this experiment, 3866 Risso's dolphin clicks were detected over a $1 \mathrm{~h}$ period. Assuming a click detection probability of $14.1 \%$ (this study), we estimate that 27418 clicks were actually produced within a $4 \mathrm{~km}$ radius of the sensor during that period. A preliminary active click rate (click rate per animal when actively vocalizing) estimate for Risso's dolphin in the GOM is 6.35 clicks/s $(\mathrm{CV}=0.05)$, with a probability of vocalization near 13\% (Frasier, 2015). Using these values, we would estimate that a single Risso's dolphin produces 2972 clicks per hour on average. Dividing the 27418 total clicks by expected clicks per dolphin per hour, we would estimate that nine animals were present in the monitored area during the $1 \mathrm{~h}$ encounter period. This is similar to average Risso's group size estimates in the GOM (7 animals/ group, $\mathrm{CV}=0.14$; Mullin and Fulling, 2004).

\section{CONCLUSION}

A Monte Carlo simulation framework was used to estimate the probability of detecting delphinids using cue and group counting methods. Simulations predict that groups are approximately three times more detectable than individual clicks, depending on the behavior and echolocation signals of the species of interest. Large, deep-diving delphinids including Risso's dolphin are expected to be detectable at greater ranges than smaller, shallow-diving species such as pantropical spotted dolphins. Agreement with in situ localizations suggests that modeling provides a reliable first-order estimate of click detectability. More detailed descriptions delphinid of echolocation click parameters as well as individual and group behaviors are needed to improve model accuracy. Parameter inputs to the model framework described here can be updated to increase model accuracy as more refined parameter estimates become available.

\section{ACKNOWLEDGMENTS}

We thank S. Murawski and S. Gilbert of the University of South Florida for project assistance. We thank I. Kerr and the crew of the $R / V$ Odyssey for assistance with HARP deployment. We thank members of the Scripps Institution of Oceanography Whale Acoustic Laboratory including $\mathrm{M}$. Roch, B. Kennedy, J. Hurwitz, J. Jones, A. Debich, R. Griswold, E. O’Neil, B. Thayre, R. Gottlieb, L. Varga, and Z. Gentes. Funding for HARP data collection and analysis was provided by the Natural Resource Damage Assessment partners (20105138) and the Center for the Integrated Modeling and Analysis of the Gulf Ecosystem (C-IMAGE) Consortium of the BP/Gulf of Mexico Research Initiative (SA 12-10/GoMRI-007). The analyses and opinions expressed are those of the authors and not necessarily those of the funding entities. This research was made possible by a grant from The Gulf of Mexico Research Initiative/C-IMAGE II. Data are publicly available through the Gulf of Mexico Research Initiative Information and Data Cooperative https:// data.gulfresearchinitiative.org/data/R4.x267.180:0010 [doi: 10.7266/N7S75D8D].

Ainslie, M. A. (2013). "Neglect of bandwidth of odontocetes echolocation clicks biases propagation loss and single hydrophone population estimates," J. Acoust. Soc. Am. 134, 3506-3512. 
Au, W. W. L. (1993). The Sonar of Dolphins (Springer-Verlag, New York), pp. 104-114.

Au, W. W. L., Branstetter, B., Moore, P. W., and Finneran, J. J. (2012a). "Dolphin biosonar signals measured at extreme off-axis angles: Insights to sound propagation in the head," J. Acoust. Soc. Am. 132, 1199-1206.

Au, W. W. L., Branstetter, B., Moore, P. W., and Finneran, J. J. (2012b). "The biosonar field around an Atlantic bottlenose dolphin (Tursiops truncatus)," J. Acoust. Soc. Am. 131, 569-576.

Au, W. W. L., and Herzing, D. (2003). "Echolocation signals of wild Atlantic spotted dolphin (Stenella frontalis)," J. Acoust. Soc. Am. 113, 598-604.

Au, W. W. L., Moore, P. W. B., and Pawloski, D. (1986). "Echolocation transmitting beam of the Atlantic bottlenose dolphin,” J. Acoust. Soc. Am. 80, 688-691.

Au, W. W. L., Pawloski, J. L., Nachtigall, P. E., Blonz, M., and Gisner, R. C. (1995). "Echolocation signals and transmission beam pattern of a false killer whale (Pseudorca crassidens)," J. Acoust. Soc. Am. 98, 51-59.

Baird, R. W., Ligon, A. D., Hooker, S. K., and Gorgone, A. M. (2001). "Subsurface and nighttime behaviour of pantropical spotted dolphins in Hawai'i," Can. J. Zool. 79, 988-996.

Buckland, S. T. (2006). "Point-transect surveys for songbirds: Robust methodologies," The Auk 123, 345-357.

Buckland, S. T., Anderson, D. R., Burnham, K. P., Laake, J. L., Borchers, D. L., and Thomas, L. (2001). Introduction to Distance Sampling: Estimating Abundance of Biological Populations (Oxford University Press, Oxford, UK), 448 pp.

Fish, J. F., and Turl, C. W. (1976). "Acoustic source levels of four species of small whales," NUC TP547, NTIS AD-A037620, U.S. Naval Undersea Center, San Diego, CA.

Frasier, K. E. (2015). "Density estimation of delphinids using passive acoustics: A case study in the Gulf of Mexico," doctoral dissertation, University of California, San Diego, CA.

Glennie, R., Buckland, S. T., and Thomas, L. (2015). "The effect of animal movement on line transect estimates of abundance," PLoS One 10(3), e0121333.

Götz, T., Verfuß, U. K., and Schnitzler, H.-U. (2006). “'Eavesdropping' in wild rough-toothed dolphins (Steno bredanensis)?," Biol. Lett. 2, 5-7.

Harris, D. V. (2012). "Estimating whale abundance using sparse hydrophone arrays," doctoral dissertation, University of St Andrews, St. Andrews, UK, pp. 10-43.

Hastie, G., Wilson, B., and Thompson, P. (2006). "Diving deep in a foraging hotspot: Acoustic insights into bottlenose dolphin dive depths and feeding behaviour," Mar. Biol. 148, 1181-1188.

Heide-Jørgensen, M. P., Bloch, D., Stefansson, E., Mikkelsen, B., Ofstad, L. H., and Dietz, R. (2002). "Diving behaviour of long-finned pilot whales Globicephala melas around the Faroe Islands," Wildlife Biol. 8, 307-313.

Helble, T., D'Spain, G., Campbell, G., and Hildebrand, J. (2013a). "Calibrating passive acoustic monitoring: Correcting humpback whale call detections for site-specific and time-dependent environmental characteristics," J. Acoust. Soc. Am. 134, EL400-EL406.

Helble, T., D'Spain, G., Hildebrand, J., Campbell, G., Campbell, R., and Heaney, K. (2013b). "Site specific probability of passive acoustic detection of humpback whale calls from single fixed hydrophones," J. Acoust. Soc. Am. 134, 2556-2570.

Hildebrand, J., Baumann-Pickering, S., Frasier, K., Tricky, J., Merkens, K., Wiggins, S., McDonald, M., Harris, D., Marques, T., and Thomas, L. (2015). "Passive acoustic monitoring of beaked whale densities in the Gulf of Mexico during and after the Deepwater Horizon oil spill," Nat. Sci. Rep. 5, 16343, 1-15.

Jensen, F. H., Wahlberg, M., Beedholm, K., Johnson, M., de Soto, N. A., and Madsen, P. T. (2015). "Single-click beam patterns suggest dynamic changes to the field of view of echolocating Atlantic spotted dolphins (Stenella frontalis) in the wild," J. Exp. Biol. 218(9), 1314-1324.

Kruse, S., Caldwell, D. K., and Caldwell, M. C. (1999). "Risso's dolphin Grampus griseus (G. Cuvier, 1812)," in Handbook of Marine Mammals, Volume 6: The Second Book of Dolphins and the Porpoises, edited by S. H. Ridgway and R. Harrison (Academic Press, San Diego, CA), pp. 183-212.

Küsel, E. T., Mellinger, D. K., Thomas, L., Marques, T. A., Moretti, D., and Ward, J. (2011). "Cetacean population density estimation from single fixed sensors using passive acoustics," J. Acoust. Soc. Am. 129, 3610-3622.

Kyhn, L. A., Tougaard, J., Thomas, L., Duve, L. R., Stenback, J., Amundin, M., Desportes, G., and Teilmann, J. (2012). "From echolocation clicks to animal density-Acoustic sampling of harbor porpoises with static dataloggers,"J. Acoust. Soc. Am. 131(1), 550-560.
Madsen, P. T., Kerr, I., and Payne, R. (2004). "Echolocation clicks of two free-ranging, oceanic delphinids with different food preferences: False killer whales Pseudorca crassidens and Risso's dolphins Grampus griseus," J. Exp. Biol. 207, 1811-1823.

Marques, T. A., Thomas, L., Martin, S. W., Mellinger, D. K., Ward, J. A., Moretti, D. J., Harris, D., and Tyack, P. L. (2013). "Estimating animal population density using passive acoustics," Biol. Rev. 88, 287-309.

Marques, T., Thomas, L., Ward, J., DiMarzio, N., and Tyack, P. (2009). "Estimating cetacean population density using fixed passive acoustic sensors: An example with Blainville's beaked whales," J. Acoust. Soc. Am. 125, 1982-1994.

Metropolis, N., and Ulam, S. (1949). "The Monte Carlo Method," J. Am. Stat. Assoc. 44, 335-341.

Mountain, D. C., Anderson, D., Voysey, G., and Brughera, A. (2013). "The effects of sound in the marine environment workbench: A simulation tool to predict the impact of anthropogenic sound on marine mammals," J. Acoust. Soc. Am. 133, 3494.

Mullin, K., and Fulling, G. (2004). "Abundance of cetaceans in the oceanic northern Gulf of Mexico, 1996-2001,” Mar. Mamm. Sci. 20(4), 787-807.

Perrin, W. F. (2001). "Stenella attenuata," Mammal. Spec. 683, 1-8.

Perrin, W. F., and Hohn, A. A., (1994). "Pantropical spotted dolphin Stenella attenuata (Meyen, 1833)," in Handbook of Marine Mammals, Volume 5: The First Book of Dolphins, edited by S. H. Ridgway and R. Harrison (Academic Press, London, UK), pp. 129-159.

Porter, M. B. (1991). "The KRAKEN normal mode program," SACLANTCEN Mem. SM-245, 198 pp.

Porter, M. B., and Bucker, H. P. (1987). "Gaussian beam tracing for computing ocean acoustic fields," J. Acoust. Soc. Am. 82, 1349-1359.

Porter, M. B., and Liu, Y.-C. (1994). "Finite-element ray tracing," in Proceedings of the International Conference on Theoretical Computational Acoustics, Vol. 2, pp. 947-956.

Rasmussen, M. H., Miller, L. A., and Au, W. W. L. (2002). "Source levels of clicks from free-ranging white-beaked dolphins (Lagenorhynchus albirostris Gray 1846) recorded in Icelandic waters," J. Acoust. Soc. Am. 111, $1122-1125$.

Rasmussen, M. H., Wahlberg, M., and Miller, L. A. (2004). "Estimated transmission beam pattern of clicks recorded from free-ranging whitebeaked dolphins (Lagenorhynchus albirostris)," J. Acoust. Soc. Am. 116, 1826-1831.

Rayleigh, L. (1945). The Theory of Sound (Dover Publications, New York), Vol. 1, pp. 96-117.

Scott, M. D., and Chivers, S. J. (2009). "Movements and diving behavior of pelagic spotted dolphins," Mar. Mamm. Sci. 25, 137-160.

Smith, A. B., Kloepper, L. N., Yang, W. C., Huang, W. H., Jen, I. F., Rideout, B. P., and Nachtigall, P. E. (2016). "Transmission beam characteristics of a Risso's dolphin (Grampus griseus)," J. Acoust. Soc. Am. 139(1), 53-62.

Thomas, L., Buckland, S., Rexstad, E., Laake, J., Strindberg, S., Hedley, S., Bishop, J., Marques, T., and Burnham, K. (2010). "Distance software: Design and analysis of distance sampling surveys for estimating population size," J. Appl. Ecol. 47, 5-14.

Urick, R. J. (1967). Principles of Underwater Sound for Engineers (Tata McGraw-Hill Education).

Ward, J., Jarvis, S., Moretti, D., Morrissey, R., DiMarzio, N., Johnson, M., Tyack, P., Thomas, L., and Marques, T. (2011). "Beaked whale (Mesoplodon densirostris) passive acoustic detection in increasing ambient noise," J. Acoust. Soc. Am. 129, 662-669.

Wells, R. S., Manire, C. A., Byrd, L., Smith, D. R., Gannon, J. G., Fauquier, D., and Mullin, K. D. (2009). "Movements and dive patterns of a rehabilitated Risso's dolphin, Grampus griseus, in the Gulf of Mexico and Atlantic Ocean," Mar. Mamm. Sci. 25, 420-429.

Wiggins, S. M., and Hildebrand, J. A. (2007). "High-frequency Acoustic Recording Package (HARP) for broad-band, long-term marine mammal monitoring," in Symposium on Underwater Technology and Workshop on Scientific Use of Submarine Cables and Related Technologies, (Institute of Electrical and Electronics Engineers, Tokyo, Japan), pp. 551-557.

Wiggins, S. M., McDonald, M. A., and Hildebrand, J. A. (2012). "Beaked whale and dolphin tracking using a multichannel autonomous acoustic recorder," J. Acoust. Soc. Am. 131, 156-163.

Zimmer, W. M., Tyack, P. L., Johnson, M. P., and Madsen, P. T. (2005). "Three-dimensional beam pattern of regular sperm whale clicks confirms bent-horn hypothesis," J. Acoust. Soc. Am. 117, 1473-1485. 